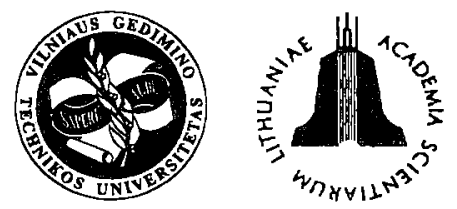

ISSN 1648-4142 TRANSPORT

http:/www.vtu.lt/english/editions

\title{
THE EVALUATION OF BRAKING EFFICIENCY OF TRACTOR TRANSPORT AGGREGATE
}

\author{
Algirdas Janulevičius ${ }^{1}$, Kazimieras Giedra ${ }^{2}$ \\ Department of Transport and Power machinery, Lithuanian University of Agriculture, \\ Studentı g. 15, Akademija, LT- 4324 Kaunas region, Lithuania, Tel.(27) 397-535
}

Received 200204 22; accepted 20020517

\begin{abstract}
The theoretical investigation of the braking process of a tractor transport aggregate is carried out. The influence of the mass of machines on the efficiency of braking is set. The dependencies of forces acting the coupler on the trailer and tractor ratio of masses $\left(\lambda_{c}\right)$, and on the difference of ratios of the brekable and whole masses of a trailer and tractor $\left(\lambda_{\mathrm{p}}-\lambda_{\mathrm{t}}\right)$, are presented.

The nomogram for operative set and the selection of the main braking parameters of various Iractor transports aggregates were established.

With the help of the nomogram it is possible to set: braking elficiency, greatest deceleration, shortest braking distance, greatest common mass of aggregate and acting forces of brakable tractor transport aggregate.
\end{abstract}

Keywords: tractor, trailer, mass, forces, braking efficiency, deceleration, braking distance.

\section{Introduction}

A great part of carriage in agriculture is carried out on the field roads, fields, virgin soils and stubbles. It is necessary in winter to drive on snow-covered fields. Therefore wheeled tractors with trailers (tractor transport aggregates) are used in agriculture. In agriculture of Lithuania there are some tractors and tractor type trailers which have one-axle brakable wheels. Sometimes transport aggregates are made with only tractor brakable wheels. It is unclear whether a loaded vehicle form such braking force $F_{s t}$, which satisfies deceleration $a_{s t}$ (required by standard [1, 2]) of a vehicle. Therefore composing various tractor transport aggregates a good analysis of compatibility of braking systems of tractors and trailers, capability and efficiency of braking is necessary.

The main evaluation characteristics of braking efficiency of tractor transport aggregates are: braking distance $s_{s t}(\mathrm{~m})$, deceleration $a_{s t}(\mathrm{~m} / \mathrm{s})$ and stability at the moment of braking. Deceleration $a_{s t}$ is calculated by formula [3]:

$$
a_{s t}=F_{s t} / m \text {, }
$$

here $\mathrm{m}$ - mass of vehicle, $\mathrm{kg} ; F_{s t}$ - total braking force, $N$.

The deceleration of vehicles $a_{s t}$ is evaluated and standardized by braking efficiency $z$ expressed by per-

'E-mail: jalgirdas@tech.lzuu.lt

${ }^{2} \mathrm{E}$-mail: giedra@info.lzua.lt cents [4]. The efficiency of vehicles brakes $z$ tested on the road is calculated by formula [3, 4]:

$$
z=a_{s t} / g \times 100 \%,
$$

here $g$ - acceleration of free falling body, $m s^{2}$.

A. A. Maschensky (А. А. Мащенский) [5], J. E. Atamanov (Ю. Е. Атаманов) ir V. V. Guskov (В. В. Гуськов) [6] analyzing braking dynamics of automobile and tractor train forces acting on the coupler mathematically expressed by formula:

$$
F_{s k}=\frac{\left(a_{p}-a_{t}\right) m_{t} m_{p}}{m_{t}+m_{p}},
$$

here $m_{t}, m_{p}-$ vehicle and trailer mass, $\mathrm{kg} ; a_{t}=F_{s t t} / m_{t}$ and $a_{p}=F_{s t} / m_{p}-$ vehicle and trailer proportional deceleration, $\left(\mathrm{ml}_{\mathrm{s}} \mathrm{s}^{2}\right) ; F_{s t} p$ ir $F_{s t p}$-vehicle and trailer total braking forces, $N$.

Introducing equation $m_{t} / m_{p}=\lambda_{c}$ to the formula (3) they presented equation, expressing the force acting on the coupler:

$$
F_{s k}=\frac{\left(a_{p}-a_{t}\right) \lambda_{c} m_{t}}{1+\lambda_{c}} .
$$

In the equation (4) presented by A. A. Maschensky (A. А. Мащенский) and analogical equation presented by J. E. Atamanov (Ю. Е. Атаманов) and V. V. Guskov (B. В. Гуськов) forces acting the coupler expressed by really not existing tractor and trailer proportional decel- 
erations. Really the deceleration of a tractor and a trailer at the braking process is equal. It is difficult to evaluate the braking efficiency and forces acting the coupler using equations (1) and (4) in tractor transport aggregate with unbrakable wheels.

\section{Research Aims}

The aims of the research are: to carry out theoretical investigations of the braking efficiency of a tractor transport aggregate, to set braking forces acting a tractor, a trailer and a coupler, their mutual dependencies and influence on braking efficiency, to make the graphics and methodics seting the main braking parameters of a tractor transport aggregate.

\section{Theoretical Research of the Main Braking Param- eters of a Tractor Transport Aggregate}

Some methods are used for braking tractors and automobiles with trailers: 1) shifting off the engine and decreasing the speed due to road resistance (such braking is effective and right on bad roads or driving up the hill); 2) with connected engine, but decreased or switched off fuel supply (such braking is used driving down the hill);

3) making additional resistance to the motion by brakes. Vehicles on the roads commonly use additional means (brakes) for braking.

The motion of brakable separate machines of a tractor transport aggregate (Fig 1), when $F_{s t} p>F_{s t}$ is possible to be writen by differential equations:

$$
\left\{\begin{array}{l}
m_{t} a_{s t}=-F_{s t t}-F_{s k}, \\
m_{p} a_{s t}=-F_{s t p}+F_{s k},
\end{array}\right.
$$

here $m_{t}$ and $m_{p}$ - mass of a tractor and trailer, $\mathrm{kg} ; a_{s t}-$ deceleration of a tractor transport aggregate, $\mathrm{m} / \mathrm{s}^{2}$;
$F_{s t ~}$ and $F_{s t p}$-vehicle and trailer total braking forces $N$; $F_{s k}$ - force acting on the coupler.

The construction of a coupler influences the braking dynamics of a tractor transport aggregate [7]. In this article the braking dynamics of a tractor transport aggregate with a rigid coupler is being analyzed. Such couplers are mostly used in agriculture.

Braking forces $F_{s t}$ are created by the torques of brakes $M_{s t}(N m)$, acting the brakable wheels:

$$
F_{s t}=\sum M_{s t} r_{r}
$$

here $r_{r}$-rolling radius of the wheel, $m$.

It is known that the greatest braking force is available when the wheels are still rolling [8]. The greatest grip coefficient is obtained at $20-30 \%$ of wheel slip of a braking vehicle, when a wheel still turns. When a wheel slips $100 \%$ of the braking force becomes less about $10-20 \%[8,9]$. The grip coefficient mostly depends on road or field structure [10]. Furthermore, when not all the wheels are braked, the braking force must be added to the force of wheel rolling resistance. This force increases particularly on a soft surface. In agriculture it is impossible to increase greatly the load of brakable wheels due to soil squeeze [11]. The greatest braking force $F_{s t \text { max }}$ consists of wheel grip force $F_{\varphi \max }$ and rolling resistance force $F_{k}$ :

$$
F_{s t \text {.max }}=F_{\varphi}+F_{k}=\varphi \quad R_{s}+F_{k},
$$

here $\varphi$ - grip coefficient; $R_{s}$ - total normal road reaction to the brakable wheels, $N ; F_{k}$-rolling resistance force, $\mathrm{N}$.

When the vehicle is being braked on the horizontal road:

$$
F_{s t . \max }=\varphi g m_{s t}+k m g,
$$

here $m_{s t}$ - brakable mass $(\mathrm{kg})$, id est. mass of aggregate falling on the brakable wheels.

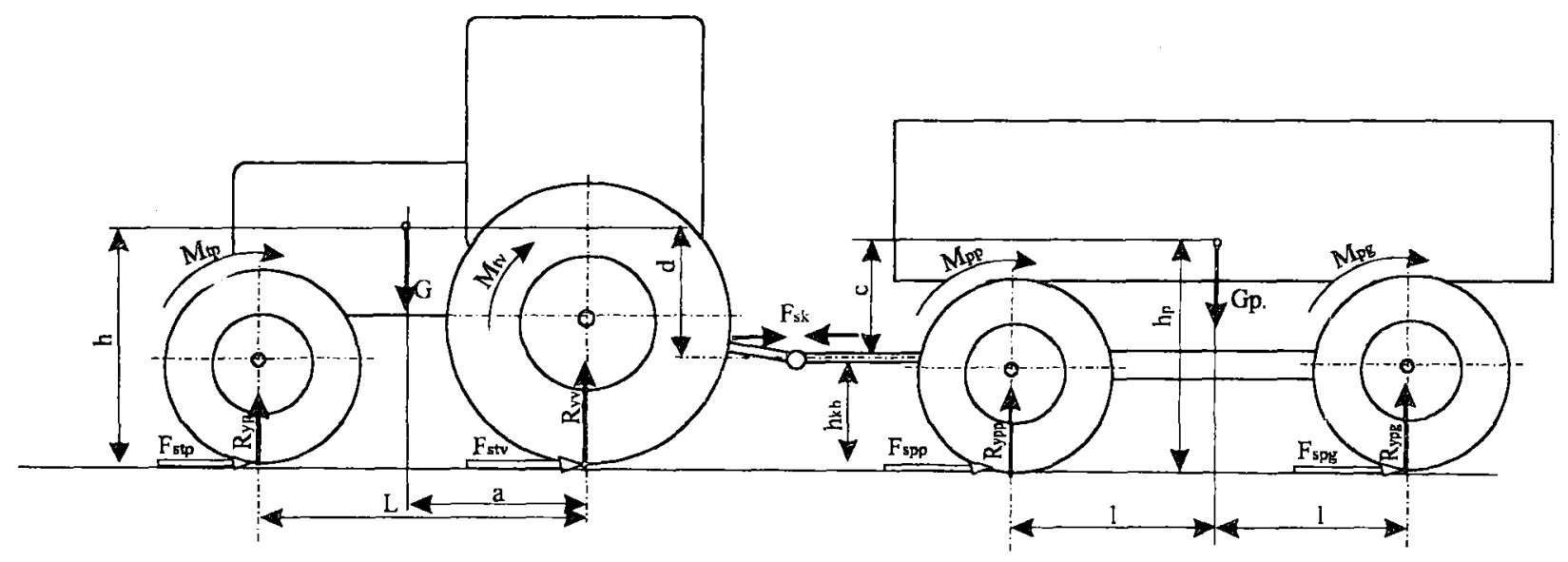

Fig 1. The scheme of forces acting the tractor transport aggregate at the moment of braking 
Evaluating tractor and trailer brakable mass:

$F_{s t}=\varphi g m_{s t} t$ and $F_{s t} p=\varphi g m_{s t} p$ the system of equations (5) can be written:

$$
\left\{\begin{array}{l}
m_{t} a_{s t}=-\varphi g m_{s t}-F_{s k}, \\
m_{p} a_{s t}=-\varphi g m_{s t p}+F_{s k} .
\end{array}\right.
$$

here $m_{s t t}$ and $m_{s t p}$ tractor and trailer brakable mass, $(\mathrm{kg})$.

Eliminating $a_{t p}$ from equation (9) it is possible to found $F_{s k}$ :

$$
F_{s k}=\varphi g\left(\frac{m_{s t} p}{m_{p}}-\frac{m_{s t t}}{m_{t}}\right) \frac{m_{t} m_{p}}{m_{t}+m_{p}} .
$$

The mass ratio of tractor and trailer $m_{p} / m_{t}$ marked by $\lambda_{c}$ the equation (10) is written:

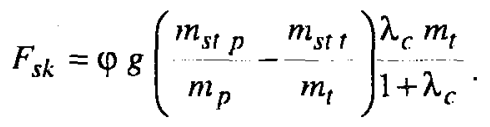

Using the equation (11) it is possible to affirm that forces acting the coupler of a tractor transport aggregate depend on grip coefficient, mass of a tractor, ratio of mass of a trailer and tractor and on the difference of ratio between brakable and whole mass of a trailer and a tractor. The ratio of brakable and whole mass of a trailer $m_{s t} p / m_{p}$ marked by $\lambda_{p}$ and ratio of brakable and whole mass of a tractor marked by $\lambda_{t}$ the equation (10) is written:

$$
F_{s k}=\varphi g\left(\lambda_{p}-\lambda_{t}\right)_{1+\lambda_{c}}^{\lambda_{c} m_{t}}
$$

The dependence of forces $F_{s k}$ acting the coupler from the trailer and tractor ratio of mass $\lambda_{c}$ on the flat road, when $\lambda_{p}-\lambda_{t}=$ const $>0$ is presented in Fig 2 .

The ratio of brakable and whole mass of the trailer and tractor changes from 0 to 1 , ed. est.: within the limits $0 \leq \lambda_{p} \leq 1 ; 0 \leq \lambda_{t} \leq 1$.

When tractor transport aggregates trailer is braked by all wheels $\lambda_{p}=1$. Analogically, when a tractor is braked by all wheels $\lambda_{t}=1$. If in a tractor transport aggregate a trailer or a tractor is not braked $\lambda_{p}=0$ or $\lambda_{t}=0$. Therefore in a tractor transport aggregate variation limits of ratios difference of brakable and whole masses of the trailer and tractor will change from +1 to -1 , ed. est. $-1 \leq\left(\lambda_{p}-\lambda_{t}\right) \leq 1$.

On the horizontal road the dependence of forces $\left(F_{s k}\right)$, acting the coupler from the difference of ratio brakable and whole masses of the trailer and tractor $\left(\lambda_{p}-\lambda_{t}\right)$ is presented in Fig 3 .

Forces $F_{s k}$ acting the coupler, (Figs 1 and 3 ) increase and approach $F_{s k}^{\prime} \cong \varphi g\left(\lambda_{p}-\lambda_{t}\right) m_{t}$, increasing the ratio of mass of tractor and trailer $\lambda_{c}$ at the same difference of the ratio between brakable and whole mass of the trailer and tractor $\left(\left(\lambda_{p}-\lambda_{t}\right)=\right.$ const $)$. Forces on the coupler

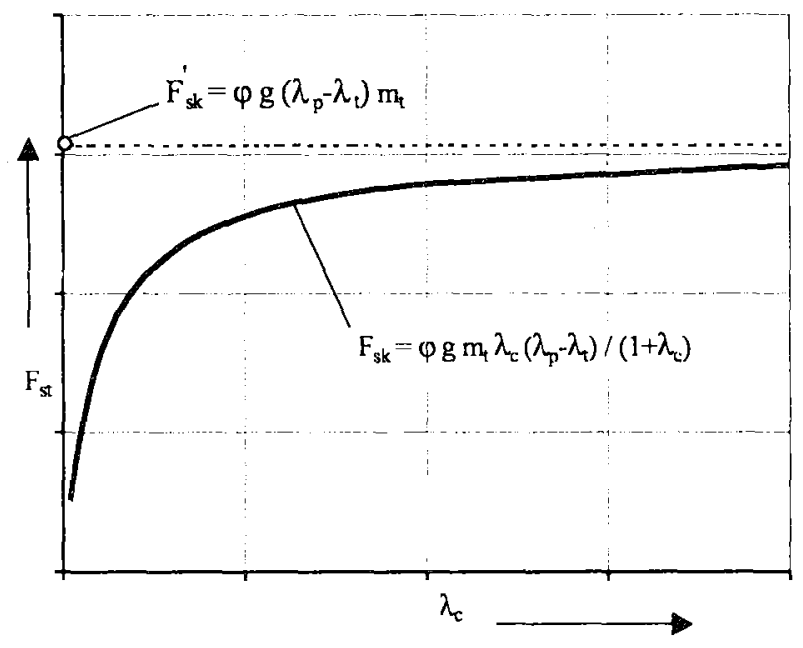

Fin 2. The dependence of forces $F_{s k}$ acting the coupler from the ratio of masses $\lambda_{c}$ of trailer and tractor

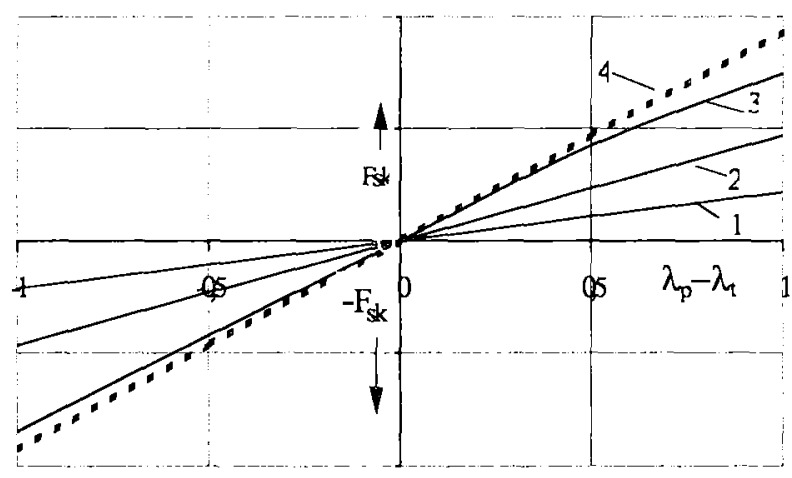

Fig 3. The dependence of forces $F_{s k}$ acting the coupler from difference of the ratio of brakable and whole mass of the trailer and tractor $\left(\lambda_{p}-\lambda_{t}\right) ; 1,2,3$ - variation according equation (12), when $\lambda_{c 1} \leq \lambda_{c 2} \leq \lambda_{c 3} ; 4$ - variation according equation $F_{s k}^{.2} \cong \varphi g\left(\lambda_{p}-\lambda_{t}\right) m_{t}$

$F_{s k}=0$, when $\lambda_{p}-\lambda_{t}=0$, that is, at the same ratio of brakable and whole mass of trailer and tractor $\left(\lambda_{p}=\lambda_{t}\right)$. The coupler will be pulled of brakable tractor transport aggregate, at $\lambda_{t}<\lambda_{p}$. At $\lambda_{t}>\lambda_{p}$ the coupler will be pressed, because force $F_{s k}$ becomes negative.

On the horizontal road the dependence of forces $\left(F_{s k}\right)$, acting the coupler from the trailer and tractor ratio of mass $\lambda_{c}$ and from difference of ratio of brakable and whole mass of trailer and tractor $\left(\lambda_{p}-\lambda_{t}\right)$ is presented in Fig 4.

The brakable tractor with a trailer is as a common deceleration of two joint machines. By acting of braking forces the vehicle receives deceleration:

$$
a_{s}=\frac{\left(\sum F_{s t}+\sum F_{p}\right)}{\delta_{s} m},
$$

here $F_{p}$ - forces of resistance; $\delta_{s}$ - coefficient of influence of turning mass. 
At intensive braking the speed of vehicle rapidly decreases and the air resistance in a braking process is in significant, therefore this force is rejected. So the differential equation of brakable vehicle, when the engine is disconnected is:

$$
a_{s t \max }=g\left[\left(\varphi R_{s} / G\right)+k \cos \alpha \pm \sin \alpha\right] / \delta_{s} .
$$

When the vehicle is being braked on the horizontal road:

$$
a_{s t \max }=\frac{g\left[\left(\varphi R_{s} / G\right)+k\right]}{\delta_{s}}=\frac{g\left[\varphi\left(m_{s t} / m\right)+k\right]}{\delta_{s}} .
$$

Coefficient of influence of turning mass $\delta_{s}$ is negligible when the engine is disconnected, because it evaluates only the inertia of wheels and connected with them transmission turning parts. This coefficient at braking moment $\delta_{s}=1,04 \ldots 1,05$, therefore the greatest braking deceleration on dry asphalt or concrete may reach $a_{s t \text { max }}$ $=7,5-8,0 \mathrm{~m} / \mathrm{s}^{2}[8,12]$.

The braking distance $s_{S I}$ is an important parameter of braking. The low stability of energy is used for the determination of this parameter. When the vehicle is driving at speed $v$, it has kinetic energy, which changes to work at the moment of braking. At intensive braking it is possible to write such an equation:

$$
\left(F_{s t \max } \pm F_{\alpha}\right) s_{s t \min }=\frac{\delta_{s} m\left(v_{1}^{2}-v_{2}^{2}\right)}{2},
$$

here $v_{1}$ and $v_{2}$ - speeds of a vehicle $\mathrm{m} / \mathrm{s}$ at the beginning and the end of braking.

Assuming that $F_{s t \max }=\varphi R_{s}+F_{k}$, we will get the shortest braking distance $s_{s t \text { min }}$ :

$$
s_{s t \min }=\begin{gathered}
\delta_{s} G\left(v_{1}^{2}-v_{2}^{2}\right) \\
2 g\left(\varphi R_{s}+k G \cos \alpha \pm G \sin \alpha\right)
\end{gathered} .
$$

Inserting (17) in the equation (14) the shortest braking distance will be:

$$
s_{s t \min }=\left(v_{1}^{2}-v_{2}^{2}\right), 2 a_{s t \max } .
$$

When a vehicle is being braked by deceleration $a_{s t}<a_{s t \max }$, braking distance will be $s_{s t}>s_{s t \text { min }}$, i.e.:

$$
s_{s t}=\left(v_{1}^{2}-v_{2}^{2}\right) 2 a_{s t} \text {. }
$$

The dependences of braking distance $\left(s_{s t}\right)$ on the speed $(v)$, at various braking intensiveness $\left(a_{s t}\right)$, is presented in Fig 5.

When a tractor transport aggregate is being braked on a horizontal road $(\alpha=0)$ by the greatest deceleration $a_{s t \text { max }}=g \varphi m_{s t} \quad m \delta_{s}$ to full stop $\left(v_{2}=0\right)$, the shortest braking distance will be:

$$
s_{s t \min }=\delta_{s} v_{1}^{2} \mathrm{~m} / 2 g \varphi m_{s t}=0.051 \delta_{s} v^{2} \mathrm{~m} / \varphi m_{s t} .
$$

The dependencies of the shortest braking distance on the speed, for vehicles brakable with all wheels on a horizontal road, at various driving circumstances (various $\varphi)$ are presented in Fig 6.

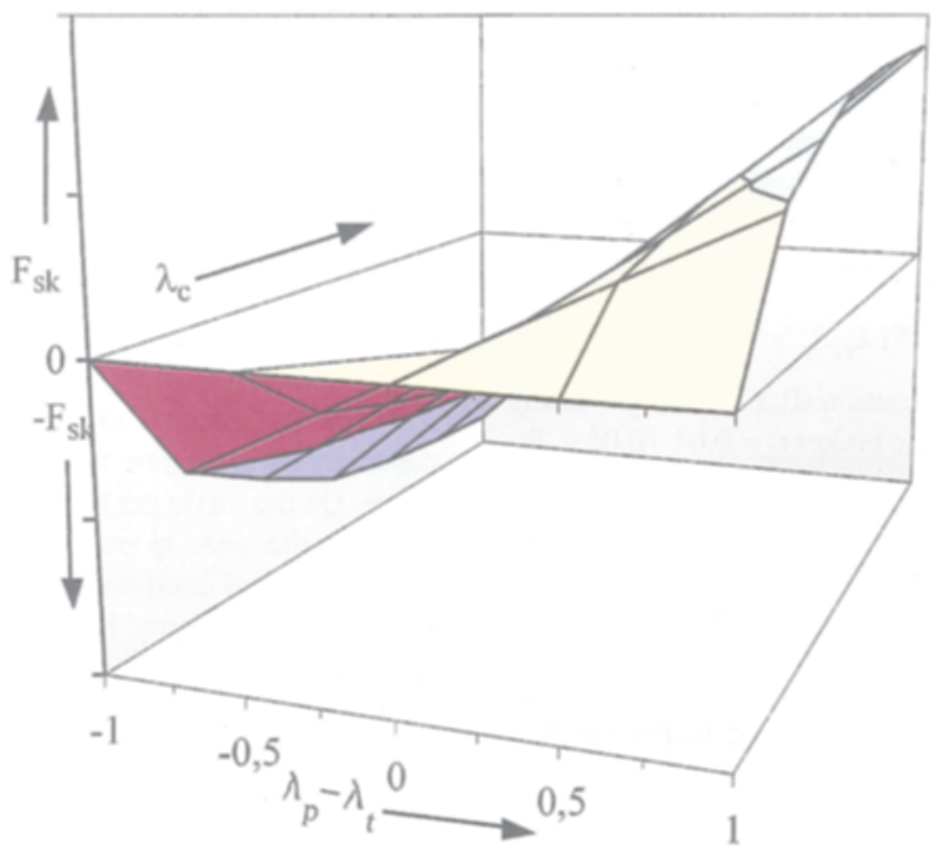

Fig 4. The dependence of forces $F_{s k}$ acting the coupler from the ratio of masses of the trailer and tractor $\lambda_{c}$ and from the difference of the ratios between brakable and whole masses of the trailer and tractor $\left(\lambda_{p}-\lambda_{f}\right)$ 


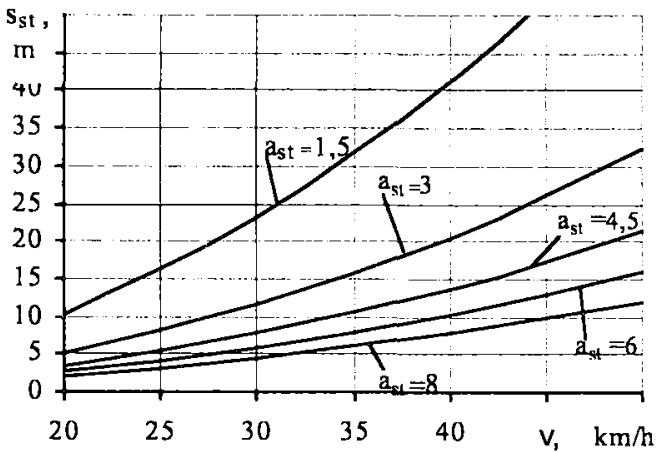

Fig 5. The dependence of braking distance $\left(s_{s t}\right)$ on driving speed $(v)$ at the correspondent decelerations $\left(a_{s l}\right)$

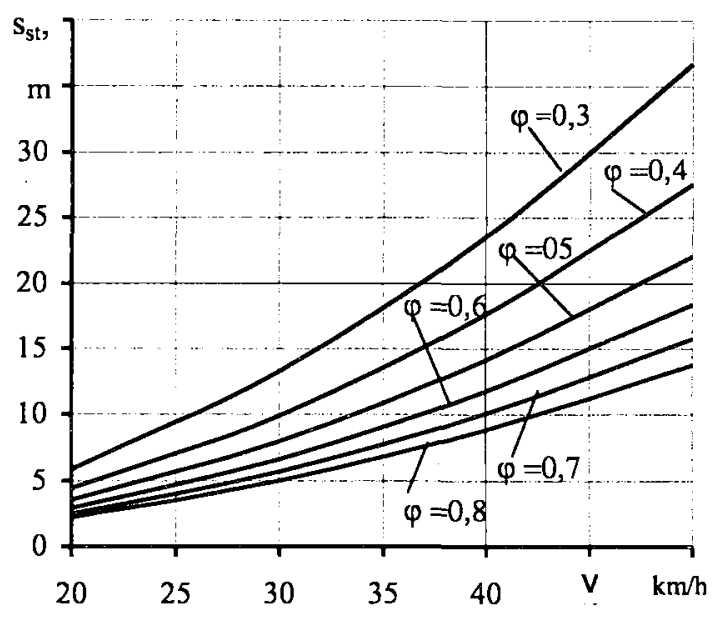

Fig 6. The dependence of braking distance $\left(s_{s f}\right)$ on driving speed $(v)$ at the correspondent traction coefficient $(\varphi)$

The real shortest distance will be a little greater than counted by the formula (20). The intensive braking begins not exactly after the obstruction has been seen.

Considering the course of real braking process, there are some formulas to count the stopping distance. Prof.

D. Velikanov $[5,12]$ suggested such a formula:

$$
s_{s t}=v\left(t_{1}-t_{2}\right)+0.051 k_{e} \delta_{s} v^{2} / \varphi,
$$

here $t_{1}$ - time of drivers reaction $(0,3-1 \mathrm{~s}) ; t_{2}$ - acting delay of brakes ( for hydraulic brakes $t_{2}=0,04-0,06 \mathrm{~s}$; for pneumatic brakes $t_{2}=0,35$, in automotive trains with pneumatic brakes $\left.t_{2} \leq 0,5 \mathrm{~s}\right) ; k_{e}$ - coefficient of braking efficiency, for cars $-1,2$, for lorries $-1,4[5,12]$.

The comparison of the shortest braking distance counted using formula (21) and the shortest real braking distance is presented in Fig 7.

According to Fig 7 it is obvious that the real shortest braking distance is about 2 times greater than the counted shortest braking distance.

\section{Analysis of Results}

The deceleration and the braking distance of a braked

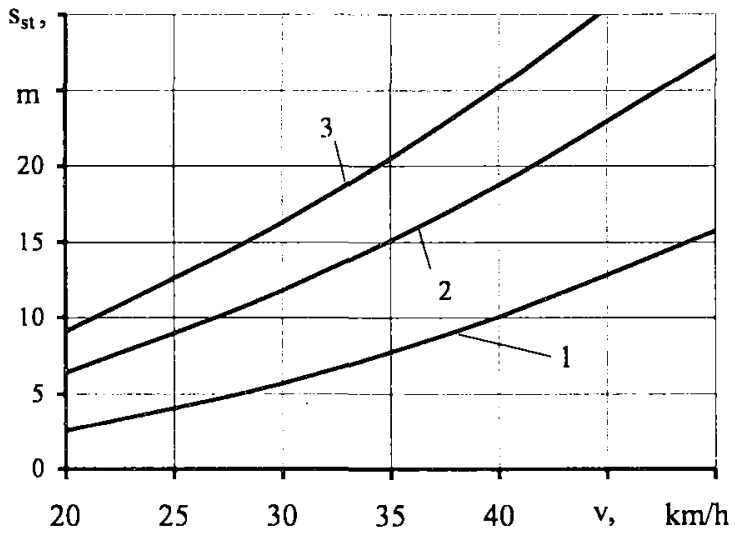

Fig 7. The dependence of braking distance $\left(s_{s i}\right)$ on driving speed $(v)$ at the $\varphi=0,7 ; 1$ - shortest theoretical braking distance; 2 - shortest real braking distance of hydraulic brakes; 3 - shortest real braking distance of pneumatic brakes

tractor transport aggregate depend on the driving speed, wheel grip with the road, brakable and all mass of aggregate and the link of these parameters.

For the determination of the braking parameters of a tractor transport aggregate and its separate machines we must solve higher presented equations and their systems. For the operative determination of these parameters based on the researched material a nomogram is made (Fig 8), with the help of which it is possible:

1. Knowing the total mass $\left(m_{a g}\right)$ and brakable mass (mass on the brakable wheels $\left(m_{s t}\right)$ of a tractor transport aggregate, road conditions, i.e. coefficient of the grip $(\varphi)$ and driving speed $(v)$, to determine the greatest deceleration of an aggregate $\left(a_{s s}\right)$, efficiency of braking $(z)$, the shortest braking distance $\left(s_{s t}\right)$ and braking forces $\left(F_{s t}\right)$.

These parameters are determined as follows: on the axle $m_{s t}$ put brakable mass of aggregate and get a point $m_{s t 1}$ (Fig 8). Through point $m_{s t 1}$ draw a vertical line $b-b$. Through the section point $\mathrm{B}$ of line $b-b$ and line of grip coefficient $\varphi$, evaluating road conditions, draw a horizontal line $c-c$. On the axle $F_{s t}$ get the greatest braking force $F_{s t \max 1}$. On the axle $m_{a g}$ putting mass of all aggregate, get a point $m_{a g}$. Through the point $m_{a g 1}$ draw a vertical line $d-d$. At the section point A of lines $c-c$ and $d-d$ get the greatest braking deceleration $a_{s t \max }$. From the center of nomogram through the point $A$ draw a line to $z$ axle. On the $z$ axle get the effectiveness of braking $z_{l}$.

On the axle $\varphi$ putting gripping coefficient $\varphi$, evaluating road conditions, get a point $\varphi_{1}$. Through this point draw a horizontal line $g-g$. Section of the line $g-g$ with the curve of speed get the point $v_{1}$. Through the point $v_{1}$ draw a vertical line $j-j$. On the section of line $j-$ $j$ with the axle $s_{s t}$ get the shortest braking distance $s_{s t} 1$.

2. Knowing the mass $\left(m_{s t}\right)$ of a tractor transport aggregate, road conditions, i.e. gripping coefficient $\varphi$ and necessary greatest braking deceleration $\left(a_{s t} \max \right)$ or efficiency of braking $(z)$ to determine full mass of aggregate $\left(m_{a g}\right)$, braking distance $\left(s_{s t}\right)$ and braking forces $\left(F_{s t}\right)$.

These parameters are set so: 


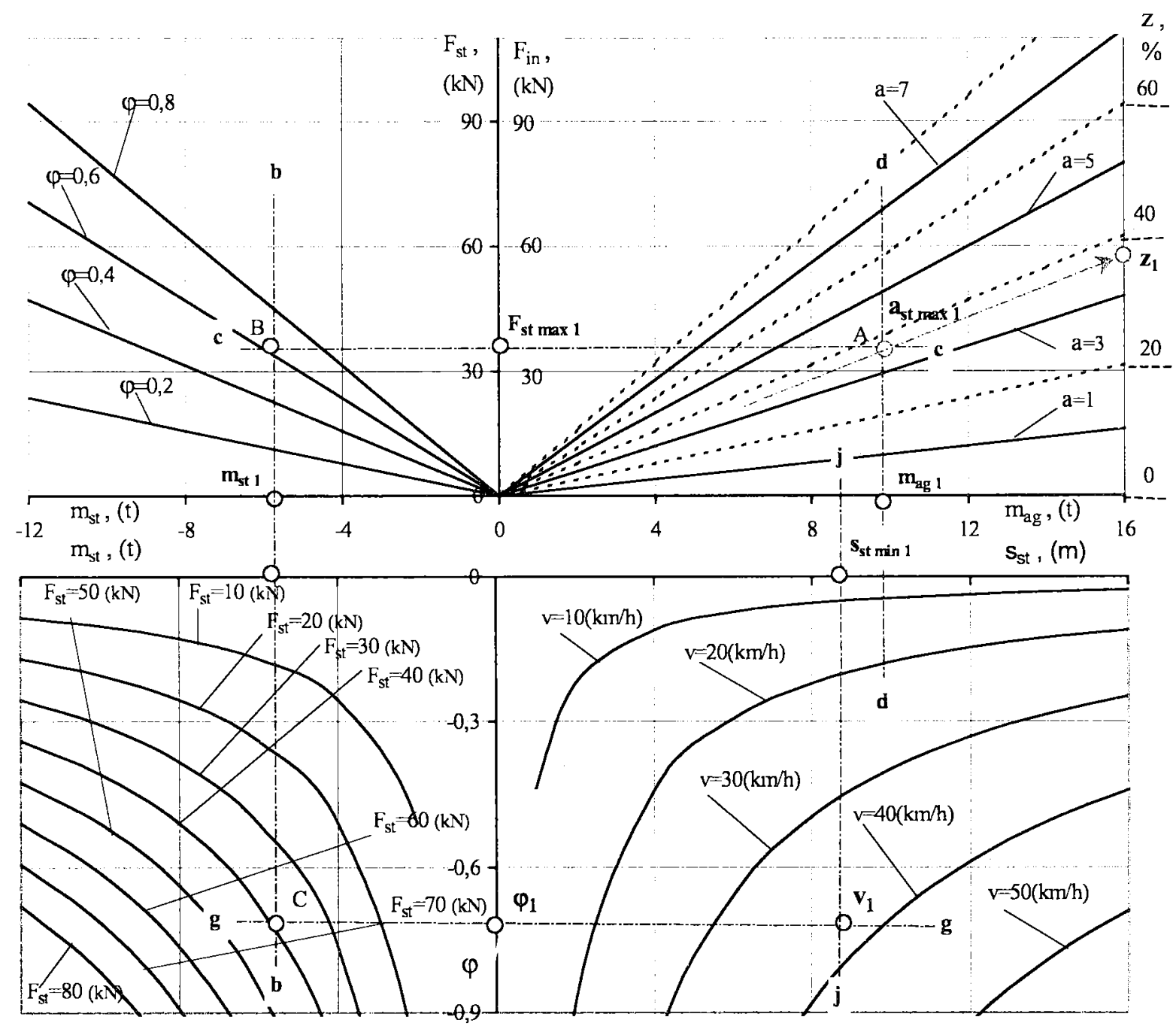

Fig 8. The nomogram of setting the main braking parameters $\left(z, a_{s t \text { max }}, s_{s t \text { min. }} F_{s t^{\prime}} m_{u x .}\right)$ of the tractor transport aggregate

The brakable mass of the aggregate is putting on the axle $\left(m_{s t}\right)$ to get a point $\left(m_{s t}\right)$. Through this point draw vertical line $b-b$. Through the section point (B) of a vertical line $b-b$ and grip coefficient $(\varphi)$ curve, evaluating road conditions, draw horizontal line $c-c$. On the axle $\left(F_{s t}\right)$ get the greatest braking force $\left(F_{s t \text { max } 1}\right)$. At the section of horizontal line $c-c$ with the line of necessary deceleration (a) or necessary braking efficiency (dotted curve), get a point A. Through this point draw a vertical line $d-d$. On the axle $m_{a g}$ get common mass ( $m_{a g !}$ ) of a tractor transport aggregate, consisting of a tractor and trailer.

On the axle $(\varphi)$ putting grip coefficient evaluating road conditions get a point $\left(\varphi_{1}\right)$. Through this point draw a horizontal line $g-g$. On the section of this line and speed curve get a point $v_{I}$. Through the point $v_{1}$ draw a vertical line $j-j$. On the axle $\left(s_{s t}\right)$ get the shortest braking distance $\left(s_{s t \min 1}\right)$.

The nomogram presented in Fig 8 is intended for setting the main braking parameters unevaluating concrete braking system coefficient of efficiency, its time of delay and reaction time of a driver.

\section{Conclusions}

1. The practical in use equation of forces acting the coupler of a brakable tractor transport aggregate the elements of which can be set from the technical data and working conditions of an aggregate is presented.

2. Increasing the ratio of mass $\lambda_{c}$ of a trailer and a tractor, the forces $\left(F_{s k}\right)$ acting the coupler increase and approach the equation $F_{s k}^{\prime} \cong \varphi g\left(\lambda_{p}-\lambda_{t}\right) m_{t}$, at the same difference of the ratios of brakable and whole masses of the trailer and tractor $\left(\lambda_{p}-\lambda_{t}=\right.$ const $)$.

3 . The forces on the coupler will be equal to zero $\left(F_{s k}\right.$ $=0)$, when $\left(\lambda_{p}-\lambda_{t}=0\right)$, i.e.: at equal ratios of brakable and whole masses of a trailer and tractor $\left(\lambda_{p}=\lambda_{p}\right)$.

4. The braking effectiveness of a tractor transport aggregate will be the greatest, when the ratios of brakable and whole mass of the trailer and tractor will be equal $\lambda_{p}$ $=\lambda_{t}=1$ ).

5. Carried out theoretical investigations of braking of a tractor transport aggregate allows to affirm that in sources of literature $[5,6]$ mathematical equations of forces 
acting the couplers of tractor and automobile transport aggregates would be right if $\lambda_{c}$ marked the ratio $m_{p} / m_{t}$, but not the ratio $m_{r} / m_{p}$

6. The theoretical nomogram made to set the effectiveness of braking and dependencies of driving speed, wheel gripping with the road, braking distance, deceleration and brakable masses and mass of aggregate is suitable for the other road transport vehicles.

\section{References}

1. Council Directive $96 / 96 / \mathrm{EC}$ on the approximation of the laws of the Member States relating to roadworthiness test for motor vehicles and their trailers. Brussels 1997.

2. Council Directive $71 / 320 / \mathrm{EEC}$ on the approximation of the laws of the Member States relating to the braking devices of certain categories of motor vehicles and their trailers. Brussels 1997.

3. Pakalnis E. The development of a check of braking effectiveness of road vehicles, the theory and the practice. Transport Engineering (Transportas), 2001, Vol XVI, No 2. Vilnius: Technika, p 55-60 (in Lithuanian).

4. The regulations and the other standard papers of State maintenance inspection of the road vehicles (Keliu transporto priemoniu valstybinių techninių apžiūru taisyklès ir kiti norminiai dokumentai). Prepared by Imbrasas P., Mickunaitis V., Pakalnis E. and other. Panevezzys, 1995, 79 p (in Lithuanian).
5. Skotnikov V. A., Mashchenski A. A., Solonski A. S. The fundamentals of theory and count of tractor and automobile (Основы теории и расчета трактора и автомобиля). Moscow: Agropromizdat, 1986. 383 p (in Russian)

6. Guskov V. V., Velev N. N., Atamanov J. E. Tractors. Theory. (Тракторы. Теория). Moscow: Mashinostrojenie, 1988. 376 p (in Russian)

7. Cypcyn V. I., Gamajunov P. P., Aleksejev S. A. The influence of the coupler construction on braking dynamics of the tractor trains. The tractors and mashines of agriculture (Тракторы и сельскохозяйственные машины), No 4, 2001, p 29-30 (in Russian).

8. Litvinov A. S., Farobin J. E. Automobile: Theory. (Автомобили: Теория). Moscow: Mashinostrojenie, 1989. $240 \mathrm{p}$ (in Russian)

9. Wong J. Theory of ground vehicles (Теория наземных транспортных средств). Moscow: Mashinostrojenie, 1989. 240 p (in Russian).

10. Upadhyaya S., Sime M., Raghuashi N., Adler B. Semiempirical traction prediction equations based on televant soil parameters. Journal of Terramechanics, 1997, 34 (3), p 141-154.

11. Jun H., Kishimoto T., Way T. R., Tauiguhi T. Three directional contact stress distributions for a pneumatic tractor tire in soft soil. Transactions of the ASAE, Vol 41, No 5, 1998, p 1237-1242.

12. Shimatonis S., Tishkevichius S. Theory of the tractors, automobiles and the engines (part II) (Traktoriu, automobiliu ir varikliu teorija. II dalis.) Kaunas: LZUA publishing centre, 1995. $287 \mathrm{p}$ (in Lithuanian). 